\title{
Foundation degree learning: an educational journey of personal development
}

Helena Herrera, David Brown and Jane Portlock

\begin{abstract}
The foundation degree is an intermediate-level qualification designed to widen participation in higher education while providing work-related skills and knowledge. It has a vocational focus and a pedagogic approach that integrates academic and work-based learning. Research into opportunities and the process of learning within foundation degrees is limited, particularly that which looks in depth at personal development occurring within these courses. This study contributes to the literature in this area, reporting on the results of a case study of the foundation degree in medicines management (University of Portsmouth). A key finding of this work was that knowledge was gained within a community of practice, and led to students' development as individuals. Motivation, learning to learn and guidance and feedback, alongside peer learning within the course, were central aspects of this process. The learning and personal development taking place resulted in increased awareness, confidence and empowerment in students, which was reported to influence their work and personal lives. However, the development of specialist work-related skills and knowledge was found to be limited, questioning the fitness for purpose of the course researched. While key aspects of the subject investigated have been described in this work, further research is needed to understand this complex phenomenon.
\end{abstract}

\section{Introduction}

\section{Background to foundation degrees}

There has been great emphasis within UK policy on widening access and improving participation in higher education (HE) while providing graduates with relevant employability skills. This has led to innovative ways of delivering HE courses to a diverse student group that increasingly includes individuals from lower sociocultural backgrounds, mature students, people in full-time employment and those with limited scope for geographical mobility and a range of circumstances influencing what studies they can undertake and how these can be funded. This paper focuses on one development resulting from this policy: the foundation degree (FD).

The FD is an intermediate-level qualification introduced in 2000 to address a 'skills gap' identified in the UK labour market (Leitch 2006, 41). It has a vocational focus that aims to effectively integrate academic and work-based learning. It is an award at level 5 in the Quality Assurance Agency for Higher Education framework, equivalent to the second year of an honours degree. It can be studied part-time or full-time and involves collaboration between employers and HE institutions. There are no nationally recognised entry requirements for FDs and individual institutions are able to define their own admissions policy, 
enabling students with a wider range of previous qualifications to access $\mathrm{HE}$ courses. On completion of a FD, students can progress to an honours degree (HD) or professional qualifications. The FD represents a new approach within HE due to its particular purpose, intended outcomes and work-based nature. Its clear and planned integration of certain characteristics not found together in other programmes makes the FD a distinct award (QAA 2010). Some of these characteristics are shown in Table 1.

\section{Table 1}

Core features of the foundation degree

Employer involvement

Ideally informed by Sector Skills Councils framework
In the design and regular review of a programme For employer / professional body recognition

Programme delivery

Flexible delivery enabling students to 'earn and learn' Accommodating the learning needs of different types of students

Development of demonstrable skills

Technical and work-specific skills relevant to new and existing members of a profession

Development of generic and employability skills

Underpinned by academic learning

Validated by the awarding HEI Underpinned by a personal development plan

Application of skills in the workplace

Demonstration of skills in relevant work

Validated, assessed and recorded work experience

Award of credits in recognition to work experience

Credit accumulation and transfer

Self-standing qualification of specific value (minimum of 240 credits)

Possible credit accumulation and transfer

Recognition of appropriate prior and work-based Arrangements learning

Progression to additional education

Articulation arrangements with at least one programme leading to a bachelors' degree with honours

These specific characteristics of the FD can make it particularly attractive to non-traditional students. The Higher Education Funding Council for England (HEFCE) indicates that FDs, particularly those offered parttime, attract a greater proportion of female and mature students, with $55 \%$ of part-time entrants in the academic year 2009/10 aged 30 or over. The literature has also shown that three-quarters of all FD students are in paid employment (Goodship and Jacks 2007). In this way, the FD represents a significant 
shift from mainstream $\mathrm{HE}$, not only due to its design, but also because of the type of students enrolling in these programmes.

\section{Foundation degrees and student learning}

Various projects have looked at different aspects of learning within FDs, providing useful insights into students' learning experiences.

Regarding general aspects of learning, in a study of 500 participants within 15 institutions (Dodgson and Whitam 2005), 92\% of students felt that their FD met their needs and $88 \%$ enjoyed their study, with the work-related elements being a strength of their course. Another project using focus groups and responses to a questionnaire provided by 300 participants (Little and Greenwood 2009) found that FDs were seen, particularly by mature students, as a way of developing while working full-time. In this study, threequarters of the respondents in paid jobs had the support of their employers. A complementary electronic survey to this research, with 184 responses from 31 courses, found that $90 \%$ of students thought employer involvement in their learning was important, despite only a third being actively supported by these (Goodship and Jacks 2007). In this work, a significant proportion of participants were satisfied with the quality of their course (94.5\%) and had gained knowledge (94.6\%) and developed work-related skills (83.7\%), with $78 \%$ of employed students considering their course relevant to their career.

With regard to teaching and learning, as many as 52\% (Goodship and Jacks 2007) and $41 \%$ of students (Little and Greenwood 2009) have found their FD more demanding than expected, with written coursework considered to be a key difficulty (Goddard and Penketh 2007). A sector-wide survey of 971 students within 119 institutions on the Early Years Sector Endorsed FD showed that only two-thirds felt explanations and support to complete assignments were provided (Snape and Finch 2006). In this study, time planning caused the most problems: commitments of the programme (56\%), pressures of work and study (69\%) and impact on family time (46\%) were major concerns. Keeping up with the academic requirements of the course (35\%) was also a common challenge after the first year, when the level of support decreased. Qualitative research conducted in parallel to this work (Knight et al. 2006) showed satisfaction with learning experiences, particularly around the individual needs of students being recognised. However, in terms of the process of learning, it reported that this was affected by some degree of disorganisation in course delivery, with sessions cancelled at short notice and deadlines too close together. This research also indicated that peer support was taking place, with students devising systems to distribute notes and handouts and share travel to the teaching sessions. The spontaneous development of an 'action group', where members helped each other, was also reported by a small-scale research project (Thurgate, Macgregor, and Brett 2007, 222), although this work did not describe details of this group's operation. 
Personal development has also been found to take place as a result of doing a FD. An increase in confidence is a recurring theme in the literature (Tierney and Slack 2005; Beaney 2006; Knight et al. 2006;

Smoothy 2006; Snape and Finch 2006; Goodship and Jacks 2007; Caestecker 2008; Dunne, Goddard, and Woolhouse 2009; Little and Greenwood 2009). This had a positive impact on the participants' jobs (Dunne, Goddard, and Woolhouse 2009), but to the detriment of personal and family life due to increased demands on their time and more responsibilities at work (Beaney 2006; Snape and Finch 2006; Wareing 2008). Reflective practice and critical thinking have been found to significantly improve (Tait and O'keefe 2004), alongside reasoning and reflective skills (Little and Greenwood 2009) and intellectual stimulation, particularly in older students (Goodship and Jacks 2007).

These findings indicate that FDs can offer productive learning and development opportunities, although the process of learning is not without challenges. They provide some, albeit limited, knowledge into how student learning is taking place within FD courses.

\section{Communities of practice}

A community of practice (CoP) is a professional support network which emerges from regular interaction, where learning takes place through the sharing of experiences and goals (Lave and Wenger 1991). In these communities, knowledge results from active engagement (Wenger 1998), is situated in experience (Lave 1996) and understood through critical reflection with others (Buysee, Sparmand, and Wesley 2003) and is not necessarily intentional (Wenger 1998). This is in contrast to the behavioural assumption that learning is an individual process based on the reception of conceptual knowledge that is best separated from other actions.

Members of a CoP are considered social beings. As they interact, their beliefs about the world are shared and influenced by the beliefs and values of others (Jonassen and Land 2000; Wenger, McDermott, and Snyder 2002), with their identities being shaped by their engagement in the CoP (Lave and Wenger 1991). Despite a CoP being a professional network, personal relationships and new ways of interacting with members can take place (Wenger, McDermott, and Snyder 2002), with learning becoming a vehicle for personal development and a way for individuals to change and develop, not only as professionals but also as individuals (Wenger 1998).

Communities of practice are found in varied sectors, for example school settings (Brandon and Charlton 2011; Fairtlough and Geyer 2011; Akerson et al. 2012; Borg 2012; Kuh 2012), research groups (Liu and Xu 2011; Murray 2012; Tummons 2012), undergraduate studies (Orsmond, Merry, and Callaghan 2011) and healthcare settings (Cornford and Carrington 2006; Lawthom 2011). While communities of practice are 
not explicitly mentioned in the literature about FDs, systems for peer support, as described in the previous section, have been found to exist in two studies (Knight et al. 2006; Thurgate, Macgregor, and Brett 2007). However, these did not explore the process of learning and personal development within the support groups, which would have provided background information on how a CoP could operate in these courses.

\section{The case studied}

The research reported was located at the School of Pharmacy and Biomedical Sciences of the University of Portsmouth. The programme studied was the FD in medicines management, a three-year, part-time, workbased course for pharmacy technicians. Its entry qualifications were the competency requirements for registration as a pharmacy technician: a Business and Technology Education Council (BTEC) qualification, based on practical work, or a National Vocational Qualification (NVQ) at level 3, based on national occupational standards.

Pharmacy technicians in the UK are pharmacy support staff who, under the supervision of pharmacists, have traditionally been involved in the procurement, manufacture, dispensing, accuracy checking and supply of medicines. Policies of workforce redesign have led to the role extension of this group, whose jobs now involve clinical practice, patient counselling and management tasks that used to be the responsibility of pharmacists. As a result of this shift, nine FDs for pharmacy technicians were developed nationwide, designed in partnership with local employers to provide workforce development that would underpin this growing range of tasks. Accreditation of prior learning and flexible delivery enabled individuals to enrol in these courses while continuing in their workplace roles. In this way, they appeared to facilitate access to and widen participation in HE by allowing individuals with varied backgrounds and already in employment to pursue HE relevant to their careers.

The University of Portsmouth pioneered the delivery of a FD for pharmacy technicians with the FD in medicines management, which had its first intake in 2004. The design of this FD was aligned with contemporary principles of adult learning. Supported by the concepts of andragogy (Knowles 1970), experiential learning (Kolb 1984) and incidental learning (Marsick and Watkins 1999) and perspectives on workplace education (Fenwick 2001), the programme underpinned learning from work in a constructivist way. The principles of self-directed learning (Biggs and Tang 2007) and reflective practice (Boud and Knights 1994) were deeply embedded in this FD. Overall, the course aimed to facilitate learning from work and at work, to develop skills, knowledge and competence.

All FDs for pharmacy technicians have had a short life-span, with the Portsmouth FD in medicines management having been the longest-standing of these programmes at the time it closed in 2013. Student and employer feedback, alongside internal and external reviews and anecdotal evidence, have not found 
significant issues with the design and delivery of this course, although they indicated that despite the course being valued by students, this was not so much the case with employers.

\section{Pharmacy technicians' learning and development}

There is limited research into pharmacy technicians' training, education and particularly learning and development, which highlights that a gap in the literature exists on this subject.

Prior work outside the UK has focused on learning for 'credentialing' in order to standardise the knowledge base and ensure patient safety. It has found that training to meet minimum competency requirements improved patient safety and that there were positive views towards supporting pharmacy technicians to engage in this learning (Sosabowski and Gard 2008; Schmitt and Desselle 2009; Alkhateeb et al. 2011).

Within the UK, and in some studies carried out overseas, research on this group's learning and development has revolved around continuing professional development (CPD). A survey study ( $n=146)$ of pharmacy technicians on the application of learning to practice showed that often, formal learning would be recorded through CPD $(70.3 \%)$, with lack of time $(n=20)$ being the main reason for not doing this. Similar findings were arrived at in a project looking at pharmacy support staff's perceptions of CPD, in which more than half of the participants thought that CPD was important (58\%), with a substantial proportion (60\%) reporting that time was a common barrier to engaging with this activity (Schafheutle, Samuels, and Hassell 2008). A comprehensive review of published literature on the attitudes to CPD of pharmacy practitioners in general also identified time as a key barrier, alongside financial costs, resource issues, facilitation and lack of support (Donyai et al. 2011).

In terms of preferences for CPD, a census questionnaire including UK-registered pharmacy technicians (Seston and Hassell 2012) indicated that the most common type of CPD activity was online learning (40.4\%), followed by workshops (38.5\%). 'Other CPD activity', which included self-directed learning, experiential learning and work-based learning, accounted for a limited number of entries (29.0\%). With regard to work-related knowledge, a survey of 148 pharmacy technicians found that the more relevant aspects were those directly related to pharmacy practice (91\%), closely followed by pharmacy theory (87\%). A smaller but still significant proportion of participants (55\%) considered interpersonal skills (such as communication and time management) relevant to their roles. After achieving minimum competency requirements, workshops were found to be the main source of further learning for pharmacy technicians, despite some individuals (33\%) preferring learning through distance teaching or self-assessment questionnaires (Elmey and Beresford 2001). 
None of these studies researched the process of learning, and no references could be found in the literature to forms of group learning involving pharmacy technicians. However, learning by participation in daily work within a CoP has been found to be a common way for pharmacists to acquire knowledge during pharmacy internships (Katajavouori et al. 2006; Christiansen, Sorensen, and Sondergaard 2007). A literature search on the personal development or development of identities in pharmacy technicians found no studies in this area, and only limited work looking at the role of junior pharmacists. This highlighted that to become a professional, group learning in the workplace was necessary, although this was in terms of knowledge being accessible rather than transferred through social interaction (Hammer et al. 2003), with mentoring playing an important role in learning professionalism (Whitely and Coetsier 1993; Schafheutle et al. 2012a).

\section{Rationale for the study and research questions}

It has been suggested that students' learning within FDs is under-examined (Harvey 2009), and the importance of knowing more about it has been highlighted (Beaney 2006). The fact that widening access and participation is an aim of these courses and that many individuals enrolling in these programmes are non-traditional students, as defined earlier, adds to the need to establish whether FDs are fit for purpose and effective in providing work-related specialist skills and knowledge using appropriate pedagogies. The literature shows that FDs can provide learning opportunities and have an effect on students' development, yet there is limited knowledge of how the process of learning relates to these aspects and to what extent it is facilitated by a FD. Some FDs are very successful, but this has not been the case for those offered to pharmacy technicians; it would be useful to identify if they were providing meaningful learning that had an impact in the workplace. Moreover, in order to be able to support FD students and for academia to effectively deliver this type of education, more needs to be known about how FD students learn and develop. In order to expand existing knowledge on this subject, this research investigated the opportunities and process of learning and personal development within a FD through the following research questions:

- What are the learning experiences of students within a FD?

- How do students learn within a FD?

- How does learning affect individuals studying for a FD?

- Does a FD offer productive learning opportunities?

\section{Methods}

This investigation was a case study of the FD in medicines management (University of Portsmouth). Due to the complexity and social aspects of learning, a qualitative approach was followed to allow in-depth 
examination. A single course was selected to gain a deeper understanding of the events and relationships involved with students' learning.

Approval was granted by the University of Portsmouth, Department of Sports \& Exercise Science/School of Pharmacy and Biomedical Science Joint Ethics Committee prior to starting this study. The main ethical issues within this research related to participants' consent and the handling of the data. This took place in compliance with the Helsinki Declaration 2008, with the study subjects being informed volunteers whose privacy was respected. Every precaution was taken to minimise the study's impact on the participants. This research was also compliant with the Data Protection Act 1998, with the data obtained from individual participants treated as anonymous and confidential.

The study collected data from focus groups, using a semi-structured interview schedule to maximise the exploration of ideas (Patton 1990). As is common in exploratory qualitative research, this was based on non-directive, open-ended questions, so participants could direct their answers to those issues which were of most importance (Bowling 2009; Robson 2011). The schedule was designed to follow an iterative process, with questions used flexibly and focused in the light of participants' responses to facilitate comprehension, probing and complete responses (Gillham 2000; Bowling 2009). The questions included in this interview schedule are shown in Table 2.

Table 2

1

2

3

4

5

6

7
Why did you want to undertake additional study and do a FD? What has your experience of learning within the FD been like? What have you learnt during your FD? How have you found that you learn better? What support have you found necessary? What do you do differently as a result of your learning? Do you find your learning within the FD useful?

All the students enrolled in the FD under investigation were invited to take part in this research through contact by academic tutors. The aims of the study and what it entailed were explained to the students on study days, when they were provided with a study information sheet. The voluntary nature of participation was highlighted and any questions responded to in order to ensure that students were appropriately informed about the research. An e-mail was subsequently sent to ask students to let the researchers know whether they wished to participate. Those who agreed were forwarded an additional copy of the study information sheet and a consent form, which had to be completed prior to taking part in the project. To capitalise on shared experiences, some focus groups were homogeneous (Kitzinger 1995), in that they were formed of students within the same year. To gain additional insights, heterogeneous groups formed of students in different years were also brought together. 
The focus groups were audio-recorded and transcribed verbatim and the transcripts uploaded to an encrypted external hard drive. They were subject to thematic analysis (Braun and Clarke 2006). During analysis, an inductive approach was followed in which concepts and themes were not anticipated but emerged from the data. These were selected based on their significance and relevance to the research questions. The process started with analysis of the first focus group transcript, with an initial list of themes and concepts drawn. This was extended and refined as the analysis proceeded with subsequent transcripts. Once all the transcripts had been analysed, they were revisited, refining themes and concepts further and checking that these were representative of the data, with relevant quotes being selected to illustrate the findings.

\section{Results and discussion}

\section{Data collection}

Data were collected from a total of 31 students in five focus groups over 14 months, from June 2008 to August 2009, after which data saturation occurred and no new themes emerged. High levels of participation were achieved as students within the course were very motivated to undertake this type of education. All participants in this project were female; there were no male students enrolled on the course. While this may have had an impact on the data collected and the conclusions that can be drawn from it, it reflects the fact that the majority of members of this professional group are female. It should also be noted that the group taking part in this research was formed of mature students, mostly with managerial or wellestablished roles within their practice base. While this is not representative of the roles generally undertaken by pharmacy technicians, it is a common feature of the type of students who enrolled in this FD. The demographic details of the study participants can be found in Table 3.

\section{Table 3}

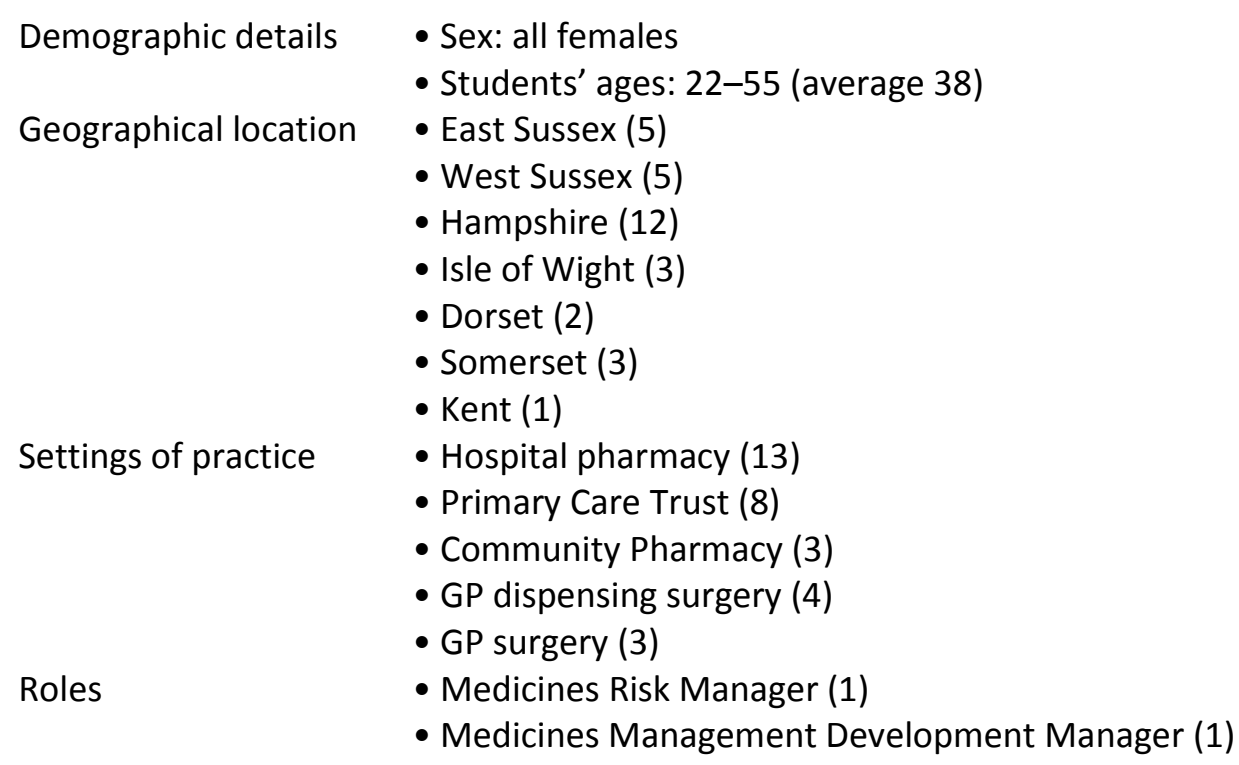


- Operations Manager (2)

- Dispensary Manager (3)

- Care Home Manager (1)

- Medicines Management Technician (7)

- Pharmacy Technician (3)

- Practice Support Technician (3)

- Sessional Pharmacy Technician (1)

- Accredited Checking Technician (4)

- Principal Technician (3)

- Medicines Liaison Technician (1)

- Chief Pharmacy Technician (1)

Time qualified

Range: $5-20$ years (average 13 )

The analysis showed several significant concepts within two main themes. These are discussed in the following sections, where quotes from the focus groups are used to illustrate the findings, attributed by assigned participant $(\mathrm{P})$ numbers.

\section{Theme 1 - Learning within a FD}

When discussing their learning experiences within the FD, four key concepts were central to the participants in this study: motivation, learning to learn, guidance and feedback and peer learning. For the students taking part in this project, their main and often only motivation to learn was to do their job 'better'. For example:

P11 I chose to do it [the FD] to expand my knowledge, and obviously patient care.

FDs can improve career prospects (Goodship and Jacks 2007), which could motivate students to engage with this qualification. This may have indicated that the goal of learning to do their job 'better' was linked to the prospect of promotion. This was not the situation in the case investigated, where students' motivation was unrelated to career benefits:

P14 So once I've finished it, that's it, I don't get any pay rise. There isn't anything to gain from it from a ...

ALL Same with us.

P14 ... pharmacy point of view, but from a personal point of view from the service that I would like to provide that I see again.

The fact that this was a group of mature students already in established employment may explain why moving up the career ladder was not a motivator. Possibly, as they had a level of responsibility within their existing jobs, they wanted to ensure their work was carried out to high standards. Opportunities to be involved in more complex aspects of patient care within their current roles did exist for these students, 
which would enable them to do their jobs 'better'. These would be in the form of enhanced roles built by further delegation of tasks from pharmacists, which this group saw as something to aspire to.

Throughout the programme, as knowledge was gained in order to do jobs 'better', increased satisfaction was achieved. Satisfaction was important to remain motivated, and this was necessary to overcome academic difficulties:

P30 If you're not self-motivated...

P26 ... you won't get, you won't do it...

ALL Yeah.

P26 ... you'd just drop out, wouldn't you?

Interestingly, in contrast with the findings of previous literature on FDs (Beaney 2006; Snape and Finch 2006; Goddard and Penketh 2007; Wareing 2008) and pharmacy technicians' learning (Donyai et al. 2011; Schafheutle et al. 2012b), time constraints were not cited as being an issue for this group. For the participants in this research this was their first experience of $\mathrm{HE}$ and as such, they had to deal with gaining a whole new set of generic and study skills. They identified this process as 'learning to learn', which was perceived as an intimidating task.

P24 Sometimes you think, 'Oh, I wish I knew what I was supposed to be doing'.

This is consistent with the findings of other studies (Snape and Finch 2006; Goddard and Penketh 2007; Goodship and Jacks 2007; Little and Greenwood 2009), where challenges in keeping up with a FD were reported. For mature students used to traditional forms of teaching and learning, it can be difficult to apply self-directed learning principles (Jossberger et al. 2010), where they have the responsibility for managing their learning experiences (Merriam and Caffarella 1998). This is illustrated in the following quote:

P1 It's very difficult because we are all of the age where we went to school and we did homework and had exams. So it's very difficult to go from that to learning by yourself and a more touchy-feely education as I call it, where it's all a bit hazy boundaries.

This circumstance was further complicated by the work-based nature of the FD and the need for students to adapt to seeing work as a context in which learning takes place (Longhurst 2009). It would be expected that this type of course would include a relevant 'study skills' module that would aim to address issues students may encounter with 'learning to learn'. This was the case in the course investigated, despite the lack of reference students made to it when they discussed their difficulties. This would indicate that this 
module had not been effective in supporting the development of the necessary underpinning generic and study skills. Despite the fact that similar difficulties have been found in other studies (Snape and Finch 2006; Goddard and Penketh 2007; Goodship and Jacks 2007; Little and Greenwood 2009), it is possible that there were non-identified underlying issues with the design or delivery of this course, rather than with the students' capacity to adapt to a new approach to learning.

The participants in this project were self-selecting students who chose to do a FD. Possibly as a result of their motivation and having pro-active personalities, able to adapt to change (Brockett and Hiermstra Brockett and Hiemstra, 1991; Candy 1991), they slowly developed into self-directed learners. There is evidence that self-directed learning leads to deeper and more reflective learning (Brockett and Hiemstra 1991; Black and Plowright 2009), in contrast with surface levels of processing (Marton and Säljö 1976a, 1976b). This was perceived by this group very early on in their FD:

P24 The guidelines are there, but it's up to you to go out and learn. You know, you're not actually being taught anything in parrot fashion, so you're going to retain more of what you've picked up.

In order to adapt to self-directed learning and to become deep learners by 'learning to learn', guidance and feedback were considered important.

P27 When we get the feedback and discuss how to change things and what to do, that's a huge difference.

While references to the need for support to FD students exist in the literature (Knight et al. 2006; Snape and Finch 2006), it was clear that in the case under investigation, this was in the form of face-to-face oral feedback. This may in part explain why a taught study skills module did not seem to have effectively addressed this issue. For example:

P21 ... because it [feedback] was given in person is something that I'll probably remember for a long time.

P25 You could discuss it. It wasn't just written feedback. You were there to have a one-to-one conversation about it.

It therefore appeared that one-to-one support was necessary to discuss individual queries with a tutor or a mentor. In pharmacy, mentoring has been found to play a critical role in the development of attitudes and behaviours, leading to increased professional development (Whitely and Coetsier 1993; Schafheutle et al. 2012a). Despite the students in this programme having the opportunity to get face-to-face feedback 
from a work-based tutor acting as a mentor, they did not use this support. The following quote illustrates this point:

P25 I hardly go to my [work-based] tutor at all, actually.

P30 All mine [coursework] is on my own.

P27 I don't go to her [work-based tutor] either.

It would have been interesting to explore in depth what led to these students' lack of interaction with work-based tutors, and whether this had any relation to the students needing to adapt to seeing work as an environment for learning. As this FD was a work-based course, aiming to develop work-related skills, the contribution of work-based tutors would have been thought to be central to students' learning. It is possible that as these students had senior positions, this led to a preference for not openly discussing learning needs in their workplace. One significant factor that would also explain the students' limited interest in seeking help from their work-based tutors was associated with the fact that they enjoyed peer learning (Knight et al. 2006; Thurgate, Macgregor, and Brett 2007):

P11 We've learned a lot from each other, haven't we?

ALL Yeah.

P15 We do support each other.

The shared goal of learning to do their jobs 'better', their common professional identities (Hara 2009) and the pro-active personal attributes of these students (Raymond, Butt, and Townsend 1992; Wenger, McDermott, and Snyder 2002; Glazer and Hannafin 2006) acted as the mechanisms which formed a CoP within this FD. This may have been further facilitated by the fact that all these were female mature students. The social nature of learning within a CoP is shown by its members' needs for relationships and, as described earlier in this section, the importance of sharing feedback (Cornford and Carrington 2006). In the case under investigation, one participant explained how contact with her fellow students was very important:

P21 When we get together, it all makes sense. When I go away I'm kind of confident that I'm doing okay, but I just love when we meet up and, and I ask someone what they're doing, and it's similar to what l'm doing.

In this way, a sense of good practice was established, and successes and challenges were shared within the CoP. The fact that the roles and responsibilities of these pharmacy technicians varied, as a result of delegation of tasks by pharmacists, further enriched the exchange of ideas. This made engagement within 
the CoP more productive, as this is dependent as much on diversity as it is on homogeneity (Wenger 1998). For example:

P25 We're all in different settings, so we're all learning from each other. P30 Yeah.

P25 I just think that it's nice that you get different people's views on everything and how different people are working.

These FD students' motivation, learning and participation in a CoP had a marked influence on their personal development, which is examined in the following section. Surprisingly, no references were made to their impact on the gaining of specific skills and knowledge relevant to the students' roles. It therefore appeared that it was the process of learning and gaining knowledge, rather than its outcome, that was felt to be at the core of the learning experiences of this group of students.

\section{Theme 2 - Personal development}

The gaining of knowledge and contact with a CoP led to students' personal development: increased awareness, confidence and empowerment were reported.

The participants in this project discussed how their behaviours and attitudes changed gradually while undertaking their FD. The following quote illustrates how one student, halfway through her first year, was facing situations differently:

P16 My friend said to me yesterday, that she feels that - we weren't necessarily talking about the course - but, how she feels that I've developed in my communication skills. I won't be the last one to talk anymore. I will join in and, you know, start a conversation, whereas before, I wasn't always the first one to talk. I suppose it [the FD] has made a difference in other aspects of my life as well.

Personal development and reflection outside an academic discourse can take place as a result of a programme of study (Smith and Bringham 2008), and references have been made to these taking place within FDs (Tait and O'keefe 2004; Tierney and Slack 2005; Knight et al. 2006; Caestecker 2008; Dunne, Goddard, and Woolhouse 2009). However, in the case researched, the course's effect on personal development was marked. This may have been related not only to the students' learning occurring as a result of undertaking a FD, but also to the significant influence that a CoP can have on its members (Conford and Carrington 2006). 
P9 The timid person I was in year one on that first induction day is not the same person as I am now. Before, I would back away from challenges, and now I actively seek out challenges and contribute. Compared to where I was, where I am now is just amazing.

Students reported increased awareness as a result of taking part in the course. Often, this was noticed as they realised they were better able to recognise their learning needs.

P10 The more you learn, the more you know you have to learn. You start thinking, 'Oh God, there's so much out there'.

In addition, knowing more about themselves as learners was facilitated, possibly as a result of 'learning to learn'. As one student explained:

P23 You have to understand yourself to a certain extent, what your own barriers are, understand why you look at something in a certain way, what's stopping you.

Self-reflection has been identified as a vehicle through which to turn experiences into learning (Symes and Macintyre 2002) through a process of exploration which arrives at new understandings and appreciations (Boud, Keogh, and Walker 1985). This could be the mechanism by which students' awareness was developed within the CoP, particularly as taught content within the course did not lead to a smooth transition of this group of students into higher education. How this increased awareness influenced the practice of these pharmacy technicians was not clear, as personal development was gradual and different ways of working progressively introduced.

P25 I don't think my work has changed as much, it's just made me very much more aware, and to look at things slightly differently, so maybe it has changed, yes.

P28 I'd probably approach things differently.

It is therefore possible that work-related skills were learned at the same time that this personal development was taking place. If so, these skills were not explicitly noticed due to the gradual nature of the changes occurring in the way these students worked. It could be argued that such a gradual change could be attributed to additional experience gained in the workplace, which may have taken place irrespective of enrolling on the course.

Awareness was defined as realising when something was wrong, even when students were unable to establish what the exact issue was. Increased awareness was felt to be useful to do their jobs 'better', but 
in order to be able to judge whether there was the need for an intervention, students felt they needed confidence, and they universally agreed that a FD provided them with this:

P14 From a confidence point of view it [the FD] makes a huge difference.

P10 Yeah, definitely. Confidence, definitely.

Other studies have found FDs raise confidence (Tierney and Slack 2005; Beaney 2006; Knight et al. 2006; Smoothy 2006; Snape and Finch 2006; Goodship and Jacks 2007; Caestecker 2008; Dunne, Goddard, and Woolhouse 2009; Little and Greenwood 2009). In the case under investigation this was partially linked to increased awareness:

P19 If you know your subject well then it will roll off the tongue easy wont it?

Building relationships with others develops self-esteem (Hodgkinson 2005), which for mature learners, such as those often taking part in FDs, can be key to their development (Richardson 2005). Both the learning taking place through a FD and the effect of the relationships developed within the CoP could have brought about this increased confidence.

In general, the confidence gained led to students feeling empowered to contribute more to their jobs than they felt had previously been the case.

P25 You're not shying away from things.

P23 That's right.

P25 You're ready to go and tackle something which you would never have done before perhaps.

This was an area of great satisfaction for the group, who felt that they were able to use their capabilities further. As seen in the previous section, being able to do their job 'better' was central for the students in this investigation, who valued having the necessary attitude to work differently. This might have been gained partly through the development of new identities as a result of belonging to a CoP, and the sense of security that this community can provide.

It is interesting that explicit mention was not made of the course supporting students' development as professionals. This would have been thought to be the key aim of this FD and a natural consequence of learning within a CoP (Wenger 1998), particularly for these students, who were highly motivated to do their jobs 'better'. It therefore remains unclear whether, in this case, measurable outputs applicable in the workplace resulted from undertaking this FD, and whether the programme was fit for purpose in the first 
place. Evidence from this study showed that students valued the course, with no reports of dissatisfaction with the design and delivery of the programme. It was also clear that more importance was placed on the development of attitudes and behaviours than on specific skills and knowledge. It may then be the case that these students already had the specialist skills and knowledge that the course aimed to provide, and they were able to start using them as a result of the new attitudes and behaviours gained. An additional possible explanation for this would need to consider the fact that defined and consistent roles and attributes for pharmacy technicians do not exist; these are shaped by delegation of tasks by individual pharmacists. Consideration of this would be required to ensure that an entirely relevant set of skills and knowledge, which can be applied in the workplace and underpin a defined set of competencies, can be provided by a FD. Only then will programmes be designed to fully deliver education specific to the roles of this group of practitioners.

\section{Conclusion}

Despite the limitations of this study with regards to its generalisability, it has provided interesting insights into opportunities and the process of learning and development within a FD. From the results generated in this work, it was apparent that learning was a challenging but rewarding experience. Within the FD investigated, the gaining of knowledge took place within a CoP and was interconnected with students' personal development. A strong motivation to do jobs 'better' enabled these students to adapt to new forms of learning, alongside the guidance and feedback received and the peer learning occurring within a CoP. While students were gaining knowledge, personal development was taking place, leading to increased awareness, confidence and empowerment. While it was clear that this personal development was useful to help them do their jobs 'better', there was limited evidence that work-related skills and knowledge were gained through the course. This raises the question of whether this programme was fit for purpose, particularly as this would be the primary aim of a FD. However, the apparent limited impact of the course on the development of new skills was not an issue for students. This would question whether they needed additional skills, or just the behaviours and attitudes necessary to be able to use existing ones more effectively. It remains unclear how the demographics of the participants in this project may have affected its results, but it is likely that the fact that they were all mature women had influenced their approach to work and learning.

If acquiring specific work-related skills and knowledge was not the primary development need of these students, it would appear that the FD was a vehicle to enable access to $\mathrm{HE}$, rather than one providing workforce development. It may be that these students were more suited to a traditional degree course but enrolled in a FD for its specific characteristics, particularly in terms of accessibility, length and compatibility with work. Moreover, because roles and attributes of pharmacy technicians were not defined in a 
consistent way, this may have led to more value being placed on personal development to adapt to potentially changing roles, rather than specific skills and knowledge.

These findings explain in part the recruitment issues encountered by the course investigated, alongside FDs for pharmacy technicians in general. These could be potentially related to a mismatch between the aims of the qualification, the intentions of the employers and the needs and aspirations of students willing to engage with this qualification. They need to be considered in order to effectively recruit students into similar FD courses, to inform the use of appropriate pedagogies and to support FD students in their learning. Only by doing so can this qualification be truly effective in widening participation in HE and providing relevant employability skills and development needs, particularly to mature students and those in full-time employment.

While key aspects of the opportunities and process for learning within a FD, alongside its effect on personal development, have been described in this work, further research is needed to understand this complex phenomenon. A similar project could be carried out looking at students' learning within other FDs; this would provide knowledge of how different settings and disciplines affect this process. Additional studies could also be undertaken on specific pedagogic aspects of FDs and how these affect students' learning. In particular, it would be interesting to look into work-based 'learning hours' and the conversion of the workplace from a working environment to a learning environment for FD students, as an apparent lack of integration of work-based and academic learning has been observed. Also, further research should focus on gathering the views of students and other stakeholders on the ways in which FDs provide workforce development. It would be particularly interesting to determine whether the focus and intended outcomes of the qualification are being achieved, rather than FDs being seen as an option for further development that can fit around people's jobs and commitments.

\section{Notes on contributors}

Helena Herrera is Senior Lecturer in Pharmacy Practice at the University of Portsmouth School of Pharmacy. Her research and teaching focuses on developing pharmacy practitioners through work-based learning.

David Brown is Professor of Pharmacy Practice at the University of Portsmouth School of Pharmacy. He has a teaching and research interest in clinical pharmacy, including medicines information supply to professionals and patients, adverse drug reactions and interactions, pharmacovigilance and risk management.

Jane Portlock is Professor of Pharmacy Education at University College London School of Pharmacy and Centre for Pharmacy Postgraduate Education Local Pharmacy Tutor for Portsmouth. 


\section{References}

1. Akerson, V., L. Donelly, M. Riggs, and J. Eastwood. 2012. Developing a community of practice to support preservice elementary teachers' nature of science instruction. International Journal of Science Education 34, no. 9: 1371-93.

2. Alkhateeb, M., K. Shields, K. Broedel-Zaugg, A. Bryan, and J. Snell. 2011. Credentialing of pharmacy technicians in the USA. International Journal of Pharmacy Practice 19, no. 4: 219-27.

3. Beaney, P. 2006. Researching foundation degrees. London: Foundation Degree Forward Publications.

4. Biggs, J., and C. Tang. 2007. Teaching for quality learning at university. 3rd ed. Maidenhead: McGraw Hill.

5. Black, P., and D. Plowright. 2009. How post-graduate pharmacy students develop professional understanding: Re-conceptualisation deep, reflective learning. Pharmacy Education 9, no. 1: 36-42.

6. Borg, T. 2012. The evolution of a teacher community of practice: Identifying facilitating and constraining factors. Studies in Continuing Education 34, no. 3: 301-17.

7. Boud, D., R. Keogh, and D. Walker. 1985. Promoting reflection in learning: A model in reflection. London: Kegan Paul.

8. Boud, D., and S. Knights. 1994. Research and development in higher education. New South Wales: HERDSA.

9. Bowling, A. 2009. Research methods in health: Investigating health and health services. Maidenhead: Open University Press.

10. Brandon, T., and J. Charlton. 2011. The lessons learned from developing an inclusive learning and teaching community of practice. International Journal of Inclusive Education 15, no. 1: 165-78.

11. Braun, V., and V. Clarke. 2006. Using thematic analysis in psychology. Qualitative Research in Psychology 3, no. 6: 77-101.

12. Brockett, R. and R. Hiemstra. 1991. Self-direction in adult learning. Perspectives on theory, research and practice. London: Routledge.

13. Buysee, V., L. Sparkman, and P. Wesley. 2003. Communities of practice: Connecting what we know with what we do. Exceptional Children 69, no. 3: 263-77.

14. Caestecker, S. 2008. Developing a foundation degree in palliative and supportive care. Forward 1, no. 12: $35-7$.

15. Candy, P. 1991. Self-direction for lifelong learning. A comprehensive guide to theory and practice. San Francisco: Jossey-Bass.

16. Christiansen, F. E. Sorensen, and B. Sondergaard. 2007. Assessment of internship in higher education. MONA 3, no. 5: 54-69.

17. Cornford, C., and B. Carrington. 2006. A qualitative study of the experiences of training in general practice: A community of practice? Journal of Education for Teaching. International Research and Pedagogy 32, no. 3: 269-82. 
18. Dodgson, R., and H. Whitam. 2005. Learner experience of foundation degrees in the North East of England: Access, support and progression. Sunderland: Aimhigher North East/Universities for North East. 19. Donyai, P., R. Herbert, Z. Denicolo, M. Pam, and A. Alexander. 2011. British pharmacy professionals' beliefs and participation in continuing professional development: A review of the literature. International Journal of Pharmacy Practice 19, no. 5: 290-317.

20. Dunne, L., G. Goddard, and C. Woolhouse. 2009. Mapping the changes: A critical exploration into the career trajectories of teaching assistants who undertake a foundation degree. Journal of Vocational Education and Learning 60, no. 1: 49-59.

21. Elmey, V., and R. Beresford. 2001. Work patterns and uptake of continuing education in a two-year cohort of New Zealand pharmacy technicians. The International Journal of Pharmacy Practice 9, no. 1: 53-7. 22. Fairtlough, A., and C. Geyer. 2011. Standards and training for work with parents across Europe: Successes and challenges in developing a community of practice. European Journal of Social Work 14, no. 4: $563-78$.

23. Fenwick, T. 2001. Sociocultural perspectives on learning through work. San Francisco, CA: Jossey-Bass.

24. Gillham, B. 2000. The research interview. London: Continuum International Publishing Group.

25. Glazer, E., and J. Hannafin. 2006. The collaborative apprenticeship model: Situated professional development within school settings. Teaching and Teacher Education 22, no. 3: 179-93.

26. Goddard, G. and C. Penketh. 2007. Students in transition: Foundation degree to honours level 6, a narrative journey of development. Paper presented at the British Educational Research Association Annual Conference, September 5-8, in London.

27. Goodship, J., and K. Jacks. 2007. The impact of foundation degrees - the student experience. Foundation Direct: Portsmouth.

28. Hammer, D., P. Berger, B. Bearsley, and M. Easton. 2003. Student professionalism. American Journal of Pharmaceutical Education 67, no. 3: 544-72.

29. Hara, N. 2009. Communities of practice: Fostering peer-to-peer learning and informal knowledge sharing in the workplace. London: Springer Berlin Heidelberg.

30. Harvey, L. 2009. Review of research literature focussed on foundation degrees. Lichfield: Foundation Degree Forward.

31. Hodgkinson, P. 2005. Reconceptualising the relations between college-based and workplace learning. Journal of Workplace Learning 13, no. 17: 521-32.

32. Jonassen, D., and S. Land. 2000. Theoretical foundations of learning environments. New YorkNY: Lawrence Erlbaum Associates.

33. Jossberger, H., S. Brand-Gruwel, H. Boshuizen, and M. Wiel. 2010. The challenge of self-directed and self-regulated learning in vocational education: A theoretical analysis and synthesis of requirements. Journal of Vocational Education and Training 62, no. 4: 415-40. 
34. Katajavouorie, N., S. Lindblom-Ylanne, and J. Hirvonen. 2006. The significance of practical training in linking theoretical studies with practice. Higher Education 51, no. 3: 439-64.

35. Kitzinger, J. 1995. Qualitative research: Introducing focus groups. British Medical Journal 311, no. 7021: 299-302.

36. Knight, T., R. Tennant, L. Dillon, and E. Weddell. 2006. Evaluating the early years sector endorsed foundation degree: A qualitative study of students' views and experiences. Nottingham: Department of Education and Skills.

37. Knowles, M. 1970. The modern practice of adult education. New York: Associated Press.

38. Kolb, D. 1984. Experiential learning: Experience as the source of learning and development. Upper Saddle River, NJ: Prentice Hall.

39. Kuh, L. 2012. Promoting communities of practice and parallel process in early childhood settings. Journal of Early Childhood Teacher Education 33, no. 1: 19-37.

40. Lave, J. 1996. Understanding practice: Perspectives on activity and context. Cambridge: Cambridge University Press.

41. Lave, J., and E. Wenger. 1991. Situated learning: Legitimate peripheral participation. Cambridge: Cambridge University Press.

42. Lawthom, R. 2011. Developing learning communities: Using a community of practice within community psychology. International Journal of Inclusive Education 15, no. 1: 153-64.

43. Leitch, S. 2006. Prosperity for all in the global economy - world class skills. HM Treasury: Final report. London.

44. Little, B., and M. Greenwood. 2009. Impact of foundation degrees in the workplace - employee and employer perspectives. Forward 1, no. 6: 12.

45. Liu, Y., and Y. Xu. 2011. The trajectory of learning in a teacher community of practice: A narrative enquiry of a language teacher's identity in the workplace. Research Papers in Education 26, no. 8: 26-32.

46. Longhurst, D. 2009. What is work-based learning? Forward 1, no. 19: 14-19.

47. Marsick, V., and K. Watkins. 1999. Facilitating learning organizations: Making learning count. Aldershot: Gower Publishers.

48. Marton, F., and R. Säljö. 1976a. On qualitative differences in learning - 1: outcome and process. British Journal of Educational Psychology 46, no. 1: 4-11.

49. Marton, F., and R. Säljö. 1976b. On qualitative differences in learning - 2: outcome as a function of the learner's conception of the task. British Journal of Educational Psychology 46, no. 2: 115-27.

50. Merriam, S., and R. Caffarella. 1998. Learning in adulthood: A comprehensive guide. San Francisco, CA: Jossey-Bass.

51. Middleton, H. 2006. What will it mean for technicians to be part of a profession? Hospital Pharmacist 13, no. 5: 411-2. 
52. Murray, R. 2012. Developing a community of research practice. British Education Research Journal 38, no. 5: 783-800.

53. Orsmond, P., S. Merry, and A. Callaghan. 2011. Communities of practice and ways to learning: Charting the progress of biology undergraduates. Studies in Higher Education 23, no. 3: 32-56.

54. Patton, M. 1990. Qualitative analysis and interpretation. Qualitative evaluation and research methods. 2nd ed. London: Sage.

55. QAA (The Quality Assurance Agency for Higher Education). 2010. Foundation degree qualification benchmark. Gloucester: The Stationery Office.

56. Raymond, D. R. Butt, and D. Townsend, eds. 1992. Context for teacher development: Insights from teacher stories. New York: Teachers College Press.

57. Richardson, J. 2005. Mature students in higher education II - an investigation of approaches to studying and academic achievement. Studies in Higher Education 20, no. 11: 5-17.

58. Robson, C. 2011. Real world research. 3rd ed. New York: John Wiley \& Sons.

59. Schafheutle, E., T. Samuels, and K. Hassell. 2008. Support staff in community pharmacy: Who they are and what do they want? International Journal of Pharmacy Practice 16, no. 2: 57-63.

60. Schafheutle, E., K. Hassell, D. Ashcroft, J. Halla, and S. Harrison. 2012a. How do pharmacy students learn professionalism? International Journal of Pharmacy Practice 20, no. 2: 118-28.

61. Schafheutle, E., C. Smith, C. Cutts, P. Higginson, and P. Noyce. 2012b. Pharmacy technicians' views of learning and practice implementation. International Journal of Pharmacy Practice 20, no. 3: 141-7.

62. Schmitt, M., and S. Desselle. 2009. Pharmacists' attitudes towards technician certification: A qualitative study. The Journal of Pharmacy Technology 25: 79-88.

63. Sosabowski, M., and P. Gard. 2008. Pharmacy education in the United Kingdom. American Journal of Pharmacy Education72, no. 5: 130-43.

64. Seston, L., and K. Hassell. 2012. First census of pharmacy technicians: 2. Qualifications, CPD, reasons for joining and plans to change work life. The Pharmaceutical Journal 288, no. 7691: 141-2.

65. Smith, A., and L. Brigham. 2008. 'Riding The Waves' project report. Buckingham: The Open University.

66. Smoothy, L. 2006. Cutting edge: The student experience. Forward 1, no. 8: 26-8.

67. Snape, D., and S. Finch. 2006. Evaluation of the early years sector-endorsed foundation degree: Report of the follow up student survey. London: Department for Education and Skills.

68. Symes, C., and J. Macintyre. 2002. Working knowledge: The new vocationalism and higher education. Buckingham: Open University Press.

69. Tait, K., and J. O'keefe. 2004. An examination of the UK early years foundation degree and the evolution of senior practitioners enhancing work-based practice by engaging in reflective and critical thinking. International Journal of Early Years Education 12, no. 1: 11.

70. Thurgate, C., J. Macgregor, and H. Brett. 2007. The lived experience: Delivering a foundation degree in health and social care. Journal of Further and Higher Education 31, no. 3: 215-23. 
71. Tierney, S., and L. Slack. 2005. Learning journeys: The experiences of students working towards a foundation degree. Journal of Vocational Education and Training 57, no. 3: 175-89.

72. Tummons, J. 2012. Theoretical trajectories within communities of practice in higher education research. Higher Education Research and Development 31, no. 3: 299-310.

73. Wareing, M. 2008. Foundation degree students as work-based learners: The mentor's role. British Journal of Nursing 17, no. 8: 532-37.

74. Wenger, E. 1998. Communities of practice: Learning, meaning and identity. Cambridge: Cambridge University Press.

75. Wenger, E., R. McDermott, and W. Snyder. 2002. Cultivating communities of practice. Boston MA: Harvard Business School Press.

76. Whitely, W., and P. Coetsier. 1993. The relationship of career mentoring to early career outcomes. Organization Studies 14, no. 6: 419-41. 